\title{
The effect of Reiki on blood hypertension
}

\author{
Efeito do Reiki na hipertensão arterial
}

Léia Fortes Salles ${ }^{1}$

Luciana Vannucci ${ }^{2}$

Amanda Salles ${ }^{3}$

Maria Júlia Paes da Silva ${ }^{1}$

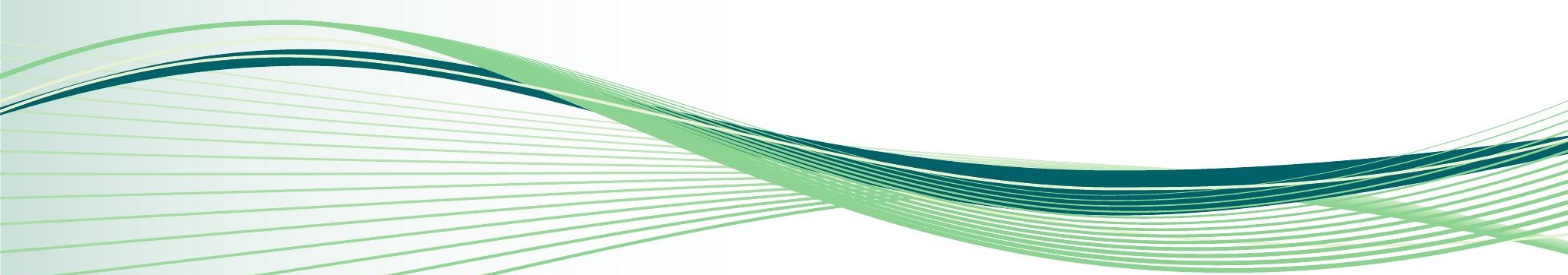

\section{Keywords}

Hypertension; Therapeutic touch; Complementary therapies; Mind-body therapies; Integrative medicine

Descritores Hipertensão; Toque terapêutico; Terapias complementares; Terapias mente-corpo; Medicina integrativa

Submitted

May 9, 2014

Accepted June 23, 2014

\section{Corresponding author}

Léia Fortes Salles

Doutor Enéas de Carvalho Aguiar

Avenue, São Paulo, SP, Brazil.

Zip Code: 05403-000.

leia.salles@usp.br

\section{DOI}

http://dx.doi.org/10.1590/1982-

0194201400078

\section{Abstract}

Objective: Determining the immediate effect of Reiki on abnormal blood pressure.

Methods: An experimental, double-blind study, in which were included 66 hypertensive patients, randomized to the three following study groups: control, placebo and experimental. The intervention lasted 20 minutes, the control group remained at rest, the placebo group received an imitation of the studied technique (mock Reiki) and the experimental group received the Reiki technique. Blood pressure was measured before and after the intervention by the same person with the same instrument.

Results: There was a decrease in blood pressure in the three groups and the reduction was greater in the experimental group, followed by the placebo and the control group. The ANOVA model for repeated measures showed a statistically significant difference among the groups ( $p<0.0001)$.

Conclusion: Reiki had a positive effect on reducing abnormal blood pressure, suggesting to be a complementary technique for the control of hypertension.

\section{Resumo}

Objetivo: Verificar o efeito imediato do Reiki na pressão arterial alterada.

Métodos: Pesquisa experimental, duplo cego no qual foram incluídos 66 hipertensos, randomizados para três grupos de estudo: controle, placebo e experimental. A intervenção teve duração de 20 minutos, 0 grupo controle permaneceu em repouso, o grupo placebo recebeu uma imitação da técnica estudada e o grupo experimental recebeu a técnica de Reiki. A pressão arterial foi aferida antes e depois da intervenção pela mesma pessoa e como mesmo aparelho.

Resultados: Houve diminuição da pressão arterial nos três grupos e a redução maior foi no grupo experimental, seguido pelo grupos placebo e controle. 0 modelo ANOVA, para medidas repetidas mostrou que houve diferença estatísticamente significativa entre os grupos $(p<0,0001)$.

Conclusão: 0 Reiki teve efeito positivo na diminuição da pressão arterial, sugerindo ser uma técnica complementar para o controle da hipertensão.

Universal Trial Number: U1111-1152-4520

Registro Brasileiro de Ensaios Clínicos: REQ 2270

'Escola de Enfermagem, Universidade de São Paulo, São Paulo, SP, Brazil.

²Vigilância em Saúde, Prefeitura de São Paulo, São Paulo, SP, Brazil.

${ }^{3}$ Fundação Getúlio Vargas, São Paulo, SP, Brazil.

Conflicts of interest: no conflicts of interest to declare. 


\section{Introduction}

Due to the rapid aging of the world population, the profile of mortality started to be characterized by complex and costly diseases, common to the advanced age and represented mainly by chronic degenerative diseases. ${ }^{(1)}$ Among them, cardiovascular diseases are a major public health problem throughout the world and, in recent decades, according to official records, the first cause of death in many countries. ${ }^{(1)}$

The increase in chronic diseases leads to a new global health challenge, which is finding new and more effective ways to prevent the onset of these diseases and its disabilities.

Complementary therapies with its holistic dimension can be useful tools for coping with this challenge, to the extent that they assists in maintaining homeostasis throughout life.

The abnormal blood pressure is the most common sign of hypertension that is recognized as the main risk factor for cardiovascular morbidity and mortality. The main cause of mortality in Brazil and worldwide is found in the group of cardiovascular diseases.

Hypertension affects more than a billion people worldwide and the prognostics indicate that by 2025 the number of people with this problem may increase by $29 \%$. $^{(2)}$ In Brazil, it is a highly prevalent disease, with rates ranging from $22 \%$ to $44 \%$. $^{(2)}$

There are several risk factors that contribute to hypertension, the main ones being obesity, alcohol consumption, sedentary lifestyle and smoking. ${ }^{(3)}$ Habits, lifestyle and adherence to treatment have strong influence in disease control. ${ }^{(3-5)}$

The harmony, quantity and balance of Vital Energy in the body are essential for the health and proper functioning of the being. At birth we have a certain level of this energy, however, at spending various amounts of it day-to-day without having a satisfactory recovery, one will probably face physical, emotional and mental imbalances, and/ or diseases.

Reiki that means universal vital energy, is a Japanese technique that aims to assist in restoring the energetic system of the body, by stimulating the natural healing processes of the body. These processes can be used to induce relaxation and treat health problems. Reiki practitioners use the approach by slight hand contact to facilitate the opening of their own energy channels and those of the patients. ${ }^{(6)}$

Reiki stimulates the body to balance itself, primarily by stimulating the immune system, predisposing it to an own re-establishment according to one's personal state. Beyond the physical aspect, the vital energy acts on psychological and emotional aspects, improving the willpower to change habits that are often deleterious to health, such as smoking, inappropriate feeding patterns and maintaining depressive thoughts and behaviors.

The nursing care aims at a comprehensive customer care, and by using Reiki, the nurses expand the possibilities of care in a simple, safe and noninvasive way.

The Nursing Council was the first council among health professions to approve and recognize the use of complementary therapies when establishing and recognizing Alternative Therapies as a specialty and/or qualification of nursing professionals. $^{(7)}$

Among the Nursing diagnoses proposed by the NANDA that justify the application of Reiki, there are the following diagnoses: Energy field disturbance; Insomnia; Sleep deprivation; Fatigue; Anxiety; Stress overload and Acute and chronic pain.

In several studies carried out by nurses, the decrease of migraine, pain, fatigue, anxiety, nausea and vomiting were found as results of the application of Reiki, as well as the increase in relaxation and accelerated cicatrization as possible benefits, besides the increase in willingness to modify unhealthy habits and styles of life. ${ }^{(7,8)}$ It is known that healthy habits help in controlling and maintaining the blood pressure at adequate levels.

There are few studies using complementary techniques for reduction of cardiovascular risk factors. A case study describes the reduction of blood pressure with techniques of the Traditional Chinese Medicine, specifically acupuncture, Tai Chi and Chi Kung. ${ }^{(9)}$ The few randomized and controlled studies with energy techniques like Meditation, Therapeutic Touch, Pranic Healing and Reiki suggest that 
they reduce anxiety and stress, factors that contribute to the imbalance of blood pressure. ${ }^{(10)}$

A study conducted in the laboratory with stressed rats showed a greater and statistically significant reduction in frequency of heart rates with the application of Reiki, in comparison with an intervention imitating the technique (placebo). None of the interventions affected the blood pressure. The study authors conclude that Reiki favors homeostasis and reduces the activity of the sympathetic nervous system. ${ }^{(11)}$

Another study demonstrates that Reiki has been effective in decreasing the heart rate in myocardial post-infarction patients, suggesting the vagal action of the technique. ${ }^{(12)}$

A randomized double-blind study of patients with burnout syndrome concludes that the application of Reiki decreases the levels of IgA (immunoglobulin A) and diastolic blood pressure, and also, that there is a statistically significant correlation between the intervention duration and the decrease of blood pressure. ${ }^{(6)}$

A systematic review on the therapeutic effect of Reiki concluded that there is still no way to evaluate the effectiveness of therapy and that further research with appropriate methodologic designs are necessary. ${ }^{(13)}$

With the increasing use of integrative practices worldwide, further research in this area is necessary in order that such practices can be safely and effectively followed. Therefore, the aim of the present study was observing the immediate effect of Reiki on abnormal blood pressure.

\section{Methods}

This is a randomized, cross-sectional, descriptive and double-blind clinical trial, in which nor the participants and neither the person checking the blood pressure have knowledge of who belongs to each group.

The survey was carried out in a health institution in the city of São Paulo, southeastern region of Brazil. In total, 170 hypertensive patients were included in the study. Using $80 \%$ confidence in- terval and 5\% error was reached a sample size of 66 patients, who were divided into three groups: control, placebo and experimental.

The inclusion criterion was blood pressure at or above $140 \mathrm{x} 90 \mathrm{mmHg}$ on the day of survey. The exclusion criteria were: being under 18 years old and the presence of symptoms consistent with hypertensive emergency, regardless of the pressure level.

After the medical consultation, patients referred by the clinic and who had blood pressure greater than or equal to $140 \times 90 \mathrm{mmHg}$ were invited to participate in the study. The volunteers were randomized and formed three groups: experimental, placebo and control.

Randomization was performed using sealed and shuffled envelopes containing one of the three groups, which were distributed and open at the moment each patient was admitted in the study.

The experimental group received Reiki. The placebo group received a 'mock Reiki' applied by someone without training in Reiki, but previously trained and following the established protocol in points of the body that were not energy centers or meridians, in random order and intercalated with periods without movements. The control group remained only at rest. The intervention lasted 20 minutes in all groups and the blood pressure was measured immediately before and after the intervention, by the same person and with the same instrument.

Although blood pressure had already been checked by the clinic physician, it was measured again, in order that both measurements (before and after the intervention) were performed under the same conditions: same instrument, professional and place, with prior rest of 15 minutes. All results were recorded in the clinical record.

At the end of the experiment, the subjects of the placebo and control groups were invited to experience the actual reiki technique, according to availability of dates and times.

Data were analyzed by number and percentage. The Chi-squared and ANOVA tests were used for statistical treatment to verify the homogeneity between the groups. The ANOVA model was used to analyze the effect of the intervention in the three 
groups (treatment p-value) and whether there was difference in outcomes among the groups (interaction p-value).

The development of study followed the national and international standards of ethics in research involving human beings.

\section{Results}

Sixty-six subjects who met the inclusion criteria were enrolled in the study: 22 in the control group, 22 in the placebo group and 22 in the experimental group.

The Chi-squared and ANOVA tests showed that the groups were homogeneous in relation to variables such as gender and age.

The maximum and mean initial values of blood pressure were higher in the Reiki group (mean of 161.0 and 128.4 , respectively) and the initial minimum blood pressure value was higher in the con- trol group (mean of 97.3). The statistical test choice took these differences into account.

The volunteers have lived with hypertension for 12 years on average, and although their blood pressure values were equal to or above $140 \times 90 \mathrm{mmHg}$, almost all reported following the recommended diet and using the prescribed medication.

The majority of the sample was comprised of female volunteers $(66.6 \%)$ with a mean age of 60 years.

The result showed a reduction in blood pressure in all three groups (treatment $\mathrm{p}$-value $<0.001$ ), but it was more pronounced in the experimental group. A statistically significant difference was also demonstrated among groups, highlighting the experimental group result (interaction $\mathrm{p}$-value $<0.001$ ), as shown in table 1.

The reduction in blood pressure was greater in the experimental group, followed by the placebo group and the control group, as shown in table 2 .

Table 1. Comparison of maximum, minimum and mean blood pressure (BP) values in the three groups by the ANOVA model

\begin{tabular}{|c|c|c|c|c|c|}
\hline \multirow{2}{*}{ Variable } & \multirow{2}{*}{ Group } & \multirow{2}{*}{$\begin{array}{c}\text { Pre-treatment } \\
\text { Mean (SD) }\end{array}$} & \multirow{2}{*}{$\begin{array}{c}\text { Post-treatment } \\
\text { Mean (SD) }\end{array}$} & \multicolumn{2}{|c|}{$p$-value* } \\
\hline & & & & Treatment & Interaction \\
\hline \multirow[t]{3}{*}{ Maximum BP } & Reiki & $161.00(19.03)$ & $147.36(19.4)$ & $<0.001$ & 0.004 \\
\hline & Placebo & $151.23(9.27)$ & 146.82(11.71) & & \\
\hline & Control & 154.05(13.19) & $150.50(15.79)$ & & \\
\hline \multirow[t]{3}{*}{ Minimum BP } & Reiki & $95.91(6.55)$ & $88.18(10.53)$ & $<0.001$ & 0.006 \\
\hline & Placebo & $91.82(5.68)$ & $90.00(6.36)$ & & \\
\hline & Control & $97.27(8.41)$ & $95.23(10.17)$ & & \\
\hline \multirow[t]{3}{*}{ Mean BP } & Reiki & $128.45(10.75)$ & $117.77(12.72)$ & $<0.001$ & 0.001 \\
\hline & Placebo & $121.52(5.44)$ & $118.41(7.96)$ & & \\
\hline & Control & $125.66(9.61)$ & 122.86(11.78) & & \\
\hline
\end{tabular}

*ANOVA for repeated measures

Table 2. Maximum, minimum and mean blood pressure (BP) values before and after the intervention in the three groups

\begin{tabular}{lccc} 
& Maximum BP before & Maximum BP after & Difference \\
Reiki & 161.0 & 147.4 & 13.6 \\
Placebo & 151.2 & 146.8 & 4.4 \\
Control & 154.0 & 150.5 & 3.5 \\
& Maximum BP before & Maximum BP after & Difference \\
Reiki & 95.9 & 88.2 & 7.7 \\
Placebo & 91.8 & 90.0 & 1.8 \\
Control & 97.3 & 95.2 & 2.1 \\
& Maximum BP before & Maximum BP after & Difference \\
Reiki & 128.4 & 117.8 & 10.6 \\
Placebo & 121.5 & 118.4 & 3.1 \\
Control & 125.6 & 122.8 & 2.8 \\
\hline
\end{tabular}




\section{Discussion}

The sample size may have not described the effect of all the involved variables, which was considered a limitation of the study results. However, the result contributes to analyze the effect of complementary therapies on episodes of arterial hypertension.

The average age of volunteers is within the age group described in the literature of patients with hypertension. ${ }^{(2)}$ Usually, women are the ones that most seek medical attention, but as both genders are affected by hypertension, it is not surprising that in this study there was a large presence of men, corresponding to approximately $36.4 \%$ of the sample. ${ }^{(2)}$

A decrease in blood pressure was expected in the three groups, with different gradations between the greater and the smaller reduction for the experimental, placebo and control groups, respectively. The control group rested for 20 minutes, and it is known that resting may help in lowering blood pressure. The placebo group received a mock Reiki and although the person responsible for the intervention was not initiated in the Reiki technique, she emits energy, as all living beings do. Finally, the experimental group received the Reiki technique, which resulted in greater decrease in blood pressure as expected in the hypothesis, corroborating the earlier presented study. ${ }^{(6)}$

The reduction in blood pressure can result from the energy balance of the body and the vagal action of the technique that facilitates homeostasis, which is an assumption shared by other authors. ${ }^{(6,12)}$

The intervention time was set as 20 minutes, because it is known that the lack of time is a factor that causes people not to participate in researches. And although in one of the studied articles ${ }^{(13)}$ the intervention duration had a statistically significant correlation with the decrease in blood pressure, we observed reduction even with the 20 minutes established in the present study.

Forming a placebo group to increase the scientific evidence of the study results was not an easy task. We all have energy that is in constant interaction with the environment and surrounding people. Thus, it takes a lot of awareness and self-knowledge to avoid this energy from suffering influence from the environment and direct it in situations where others are in need of energy, which is a frequent fact in health institutions.

Patients who had not received the Reiki technique were invited to return and try it. On this occasion, the initial and final blood pressure was also measured, and the fact that in most people the initial blood pressure was lower than at the time of the study (when volunteers had a medical consultation) called the attention. This reinforces the concept of the white coat syndrome. ${ }^{(14)}$

Randomized and double-blind studies with energy and integrative practices that concomitantly take care of emotional dimensions step into a recent paradigm in the line of research based on evidence.

More research is needed, both to strengthen the results of this investigation, as to expand knowledge and clarify other points, like the minimum time needed to benefit from the technique and the lasting of results.

\section{Conclusion}

Reiki had a positive effect on the reduction of abnormal blood pressure, suggesting to be a complementary technique for the control of hypertension.

\section{Acknowledgements}

Thanks to Carmem Luisa Pelosini Mazelli for the collaboration and management, to the staff of the institute where data collection was carried out, and to the statistician Bernardo dos Santos for performing the data analysis.

\section{Collaborations}

Salles LF and Vannucci L contributed to the project design, implementation research, discussion of the data and drafting and revision of the article. Silva MJPS collaborated with the project design, data discussion, drafting and revision of the article and Salles A with implementation of the research, discussion of the data and writing the article. 


\section{References}

1. Veras RP. [Population aging today: demands, challenges and innovations]. Rev Saúde Pública. 2009; 43(3):548-54. Portuguese.

2. Sociedade Brasileira de Hipertensão; Sociedade Brasileira de Cardiologia. VI Diretrizes Brasileiras de Hipertensão Arterial. Rev Bras Hipertens. 2010; 17(1):11-7.

3. Serafim TS, Jesus ES, Pierin AM. [Influence of knowledge on healthy lifestyle in the control of hypertensive]. Acta Paul Enferm. 2010; 23(5):658-64. Portuguese.

4. Martins LC. Physical activity level in people with high blood pressure. Rev Latinoam Enferm. 2009; 17(4):462-467. Portuguese.

5. Figueiredo NN, Asakura, L. Adesão ao tratamento anti-hipertensivo: dificuldades relatadas por indivíduos hipertensos. Acta Paul Enferm. 2010; 23(6):782-7.

6. Rodriguez LD, Morales MA, Villanueva IC, Lao CF, Polley M, Fernandez de la Penas C. The application of Reiki in nurses diagnosed with Burnout Syndrome has beneficial effects on concentration of salivary IgA and blood pressure]. Rev Latinoam Enferm. 2011; 19(5):1132-8. Portuguese.

7. Conselho Federal de Enfermagem. Resolução COFEN 197. [Internet]. [citado 2014 Mai 3]. Disponível em: http://novo.portalcofen.gov.br/ resoluo-cofen-1971997_4253.html.

8. Hulse RS, Stuart-Shor EM, Russo J. Endoscopic procedure with a modified Reiki intervention: a pilot study. Gastroenterol Nurs. 2010; 33(1):20-6.

9. Cormack BA. A multifaceted integrative approach to heart, weigh, and blood pressure normalization. [Internet]. Available from: http://www. risingtao.ca/files/RisingTao_case_study_1.pdf. (cited Nov.28/2011).

10. Ackerman DL, Cameron ME. Energy healing for anxiety and stress reduction. Clinical focus. Primary Psychiatry. 2002; 9(7):47-50.

11. Baldwin AL, Wagers C, Schwartz GE. Reiki improves Heart Rate homeostasis in laboratory . J Altern Complement Med. 2008; 14(4)417-22.

12. Friedman RSC, Burg MM, Miles P, Lee F, Lampert R. Effects Reiki on autonomic activity early after acute coronary syndrome. J Am Coll Cardiol. 2010; 56(12):995-6.

13. VanderVaart S, Gijsen VM, Wildt SN, Koren G. A systematic review of the therapeutic effects of Reiki. J Altern Complement Med. 2009; 15(11):1157-69.

14. [First Brazilian position on resistant hypertension. Hypertension Department of the Brazilian Society of Cardiology]. Arq Bras Cardiol. 2012; 99(1):576-85. Portuguese. 